\title{
RESORT PANTAI GEDAMBAAN KABUPATEN KOTABARU
}

\author{
Muhammad Reza Ady Saputra \\ Program Studi Teknik Arsitektur Fakultas Teknik Universitas Lambung Mangkurat \\ rezaadysaputra29@gmail.com \\ Dila Nadya Andini \\ Program Studi Teknik Arsitektur Fakultas Teknik Universitas Lambung Mangkurat \\ dila.andini@ulm.ac.id
}

\begin{abstract}
ABSTRAK
Pantai merupakan salah satu objek wisata yang sangat menarik. Wisata pantai menjadi salah satu ciri khas yang dimiliki oleh Kabupaten Kotabaru. Pantai Gedambaan merupakan objek wisata yang terletak di Desa Sarang Tiung Kecamatan Pulau Laut Timur Kabupaten Kotabaru. Potensi alam yang indah tentunya menjadi daya tarik wisatawan untuk berkunjung ke Pantai Gedambaan. Guna menarik wisatawan tentunya harus didukung dengan infrastruktur yang memadai salah satunya adalah resort. Resort diperlukan guna menunjang peningkatan pertumbuhan pengunjung di Pantai Gedambaan dimana dengan adanya resort lama kunjungan wisatawan akan berpengaruh pada pendapatan daerah yang secara tidak langsung akan meningkatkan perekonomian di wilayah sekitar. Permasalahan perancangan resort Pantai Gedambaan ini adalah bagaimana merancang sebuah resort yang mengembangkan potensi kawasan dengan membentuk suatu karakter berdasarkan konsep arsitektur kontekstual pada kawasan Resort Pantai Gedambaan. Untuk menyelesaikan permasalahan digunakan Metode Kontekstual Harmoni. Metode ini menekankan perancangan dengan memanfaatkan potensi alam yang diterapkan pada perancangan aspek karakteristik, lingkungan, dan pendekatan budaya pada perancangan resort ini. Kata kunci: Resort, Pantai, Gedambaan, Kotabaru, Kontektual.
\end{abstract}

\begin{abstract}
The beach is a very interesting tourist attraction. Coastal tourism is one of the characteristics possessed by the Kotabaru Regency. Gedambaan Beach is a tourist attraction located in Sarang Tiung Village, Pulau Laut Timur District, Kotabaru Regency. The beautiful natural potential is certainly an attraction for tourists to visit Gedambaan Beach. To attract more tourists, it must be supported by adequate infrastructure, one of which is a resort. The resort is needed to support the increase in visitor growth in Gedambaan Beach where the resort's long visit by tourists will affect local income which will indirectly improve the economy in the surrounding area. The problem of designing the Gedambaan Beach resort is how to design a resort that develops the potential of the region by forming a character based on the concept of contextual architecture in the Gedambaan Beach Resort area. To solve the problem, the Harmony Contextual Method is used. This method emphasizes the design by utilizing the natural potential that is applied to the design aspects of the characteristics, environment, and cultural approach to the design of this resort.

Keywords: Resort, Beach, Gedambaan, Kotabaru, Contextual.
\end{abstract}




\section{PENDAHULUAN}

Resort pantai merupakan sebuah fasilitas pariwisata yang dipergunakan sebagai tempat beristirahat untuk para wisatawan. Pada umumnya resort ialah tempat-tempat yang nyaman, memiliki pemandangan alam seperti, pantai, pegunungan, tepi sungai, ataupun tempat yang dapat dinikmati pemandangan nya oleh wisatawan. Resort pantai mengutamakan potensi alam dan laut sebagai daya tarik, pemandangan ke arah laut, daya tarik pantai, dan fasilitas- fasilitas pendukung seperti olahraga air dan olahraga pantai. Daya tarik pantai seperti itu yang seringkali dijadikan sebagai pertimbangan utama sebuah rancangan resort pantai. Adapun tipe perletakan tata massa yaitu area pesisir/ sekitar pantai maupun di area perairan pantai.

\section{Pengelolaan kegiatan pada}

tempat-tempat yang memiliki potensi pemandangan alam yang indah, untuk dijadikan tempat pariwisata bertujuan untuk meningkatkan ekonomi daerah tersebut, seperti akomodasi, hiburan,dan jasa lainnya.

Dari data Badan Pusat Statistik Kabupaten Kotabaru tahun 2018 Kabupaten Kotabaru berada pada wilayah pesisir dan pegunungan, terdiri dari 110 pulau, 21 Kecamatan dan 202 desa serta kelurahan dengan sumber daya alam yang cukup banyak. Kabupaten Kotabaru secara geografis memiliki banyak pulau, pantai, pegunungan serta kawasan hutan lindung yang masih alami.

Adapun kawasan pesisir pantai yang memiliki potensi untuk di kelola secara berkelanjutan yaitu Pantai Gedambaan. Pantai Gedambaan dulunya bernama Pantai Sarang Tiung dimana wilayah tersebut masuk dalam wilayah desa Sarang Tiung Kecamatan Pulau Laut Utara, seiring dengan perkembangan daerah wilayah pantai Sarang Tiung banyak berkembang permukiman penduduk dan pada tahun 2000 pantai Sarang Tiung diganti menjadi Pantai Gedambaan. Gedambaan memiliki arti Dambaan dimana filosofi dari Gedambaan adalah obyek wisata ini akan menjadi dambaan dan selalu diingat oleh pengunjung, sehingga diharapkan pengunjung nantinya akan kembali lagi berkunjung ke pantai Gedambaan tersebut.

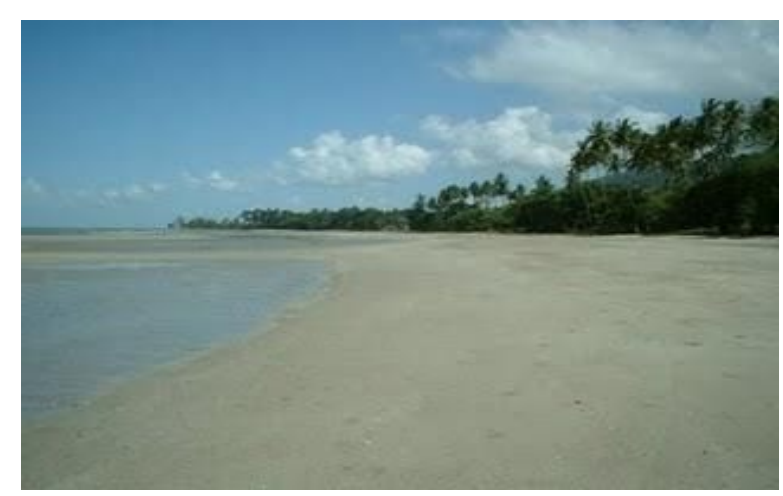

Gambar 63 Pantai Gedambaan

Jumlah Wisatawan

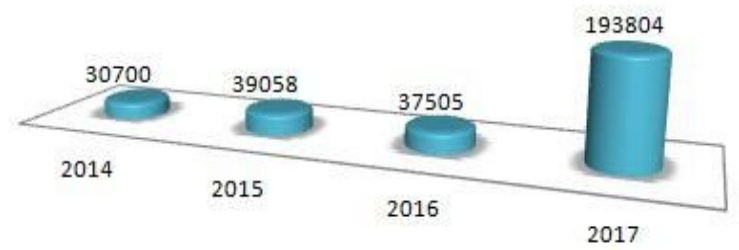

Gambar 64 Statistik 2014-2017

Berdasarkan tabel dan gambar grafik statistik (lihat gambar2) diatas, jumlah kunjungan wisatawan setiap bulannya meningkat dan dari data statistik tahun ketahun rata-rata mengalami peningkatan terutama peningkatan antara tahun 2016 dan tahun 2017 ada peningkatan yang cukup signifikan yaitu tercatat sebanyak 41.270 jumlah kunjungan wisata dengan kunjungan inap 7,03\% atau 2.900 jiwa terhadap obyek wisata yang ada di Kabupaten Kotabaru. Oleh sebab itu, resort sebagai fasilitas penunjang pariwisata dianggap perlu untuk dirancang di sekitar Pantai Gedambaan.

\section{PERMASALAHAN}

Diambil dari latar belakang permasalahan arsitektural untuk Resort Pantai Gedambaan Kabupaten Kotabaru adalah Bagaimana merancang sebuah resort yang 
mengembangkan potensi kawasan dengan membentuk suatu karakter berdasarkan Konsep Kontekstual pada kawasan Resort Pantai Gedambaan?

\section{TINJAUAN PUSTAKA}

\section{A. Definisi Resort}

Resort adalah salah satu objek kawasan yang didalamnya terdapat sarana prasarana dan akomodasi sebagai tempat berlibur dan berwisata. Beberapa definisi resort oleh beberapa sumber menurut para ahli.

Disimpulkan dari Dirjen Pariwisata (1988:13), Resort adalah sebuah perubahan tempat tinggal seseorang diluar tempat tinggalnya bertujuan untuk mendapatkan ketenangan bagi jiwa maupun rohani yang berkaitan dengan halnya kebugaran badan atau untuk berlibur dengan keluarga serta keperluan usaha lainnya.

Dan hasil kesimpulan dari Coltmant (1895:95). Resort adalah sebuah tempat yang dirancang untuk dijadikan tempat wisata bagi para wisatawan yang ingin berlibur dan berekreasi, resort tidak harus mewah cukup sederhana tetapi menampung sebuah akomodasi dan fasilitas yang baik didalamnya, dan resort sebagian besar di bangun sesuai dengan potensi alam yang dimiliki masing tempat.

\section{Karakteristik Resort}

Karakteristik resort terlihat jelas dari uraian tinjauan yang dijelaskan oleh para sumber (Coltmant (1895:95), Dirjen Pariwisata (1988:13)), antara lain:

a. Pada umumnya resort terletak pada wilayah yang memiliki potensi alam yang indah,jauh dari kebisingan lalu lintas yang ada di kota, dan pantai dan pegunungan yang indah untuk dinikmati.

b. Motivasi pengunjung untuk berlibur dan mengisi waktu luang menuntut ketersediaan fasilitas pokok adalah ruang tidur sebagai area privasi. Fasilitas rekreasi outdoor, meliputi kolam renang, pemandian air panas, joging track dan tata lansekap .

Seorang wisatawan pada dasarnya berlibur tidak hanya untuk menikmati sebuah pemandangan alam saja akan tetapi Seni dalam Arsitektur yang ada di kawasan resort itu sangat dilihat untuk kenyamanan para wisatawan

Sasaran tertuju pada para wisatawan yang akan berkunjung, berlibur, bersenang-senang, untuk menikmati pemandangan alam, pantai, gunung, dan Arsitektur yang ada di dalam kawasan resort.

\section{Jenis-Jenis Resort}

Resort memiliki beberapa jenis yaitu Mountain Resort, Seaside Resort, Spa and Health Resort, Rural Resort and Country Hotels, Wedding Resort, Themed Resorts, Sight-seeing Resort Hotel. Resort yang akan direncanakan tujukan bagi pasangan yang ingin berbulan madu sehingga jenis resort yang dipilih adalah Beach Resort.

Beach Resort adalah resort yang berada pada pantai dimana kawasan Beach Resort melibatkan pantai dan potensi pemandangan yang ada di sekitar untuk membentuk suasana yang nyaman untuk berlibur di sela kesibukan seseorang yang ingin mendapatkan tempat yang tenang dan segar.

\section{B. Tinjauan Arsitektural}

\section{Arsitektur Kontekstual}

Secara umum dan dalam garis besar konsep kontekstualisme adalah sebuah rancangan yang sesuai dengan konteks yang ingin dibangun, dan menghasilkan sesuatu visual yang selaras antara bangunan lama dengan bangunan yang baru untuk mencapai sebuah karakteristik yang baik antara bangunan dan lingkungannya. Sehingga suatu bangunan yang menerapkan kontekstualisme harus menyesuaikan konteks yang akan di jadikan objek dengan konteks yang akan dibangun untuk menggapai visual yang baik antara bangunan dan lingkungan.

Oleh sebab itu Kontekstual terbagi menjadi 2 bagian, yaitu Kontekstual Kontras dan Kontekstual Harmoni yang menjadi sebuah garis besar dalam konteks yang ingin digunakan, berikut pengertiannya:

a. Kontras (berbeda)

Menurut Brent C. Brolin, bahwa kontras bangunan kuno dengan modern dapat mencapai sebuah keharmonian untuk rasa 
yang diterapkan,tetapi kontras yang terlalu berlebihan dapat menyebabkan permasalahan pada objek itu sendiri dikarenakan terlalu menonjolkan objek baru dengan keselarasan lingkungan yang akan visualisasikan kepada lingkungan tersebut.

b. Harmoni (keserasian)

Terkadang lingkungan menginginkan keindahan dan keserasian dalam suatu objek, ini menjadikan sebuah tuntutan secara tidak langsung agar keselarasan dan keserasian dapat terjaga dengan baik, sehingga penerapan konteks yang saling menghargai satu sama lain antara bangunan dengan lingkungan tidak saling menonjolkan kelebihan masing-masing konteks, keselarasan juga didasari untuk melestarikan sebuah tradisi ataupun budaya yang ditonjolkan, sehingga karakter antara bangunan lama maupun bangunan baru bisa saling menyatu dan tidak terlihat mendominasi.

\section{METODE}

Metode perancangan yang digunakan adalah Kontekstual Harmoni yang di bagi menjadi 3 yaitu Lingkungan, Karakteristik, dan Budaya untuk membentuk sebuah konsep yang akan diterapkan pada perancangan Resort Pantai Gedambaan Kabupaten Kotabaru

Dan dari 3 hal utama itu memiliki konsep masing-masing yang akan diterapkan pada kawasan seperti Lingkungan yang menerapkan tata massa dan sirkulasi yang baik pada kawasan, Budaya yang menerapkan interior yang menjadi daya tarik bagi penghuni yang akan tinggal di resort tersebut, dan Karakteristik yang menerapkan vegetasi dan bentuk bangunan yang seimbang antara lingkungan lama dan lingkungan baru yang akan dibangun.

\section{PEMBAHASAN}

\section{A. Konsep Program}

Penerapan konsep program pada Resort Pantai Gedambaan menggunakan konsep Kontekstual Harmoni yang dikembangkan dan diambil dari Kontekstual Arsitektur. Sehingga mendapatkan sebuah Konsep Kontekstual
Harmoni Arsitektur yang menjadi dasar penerapan pada sebuah kawasan yang ingin dirancang.

Berikut adalah skema dari Arsitektural Harmoni yang akan digunakan untuk Resort Pantai Gedambaan Kabupaten Kotabaru :

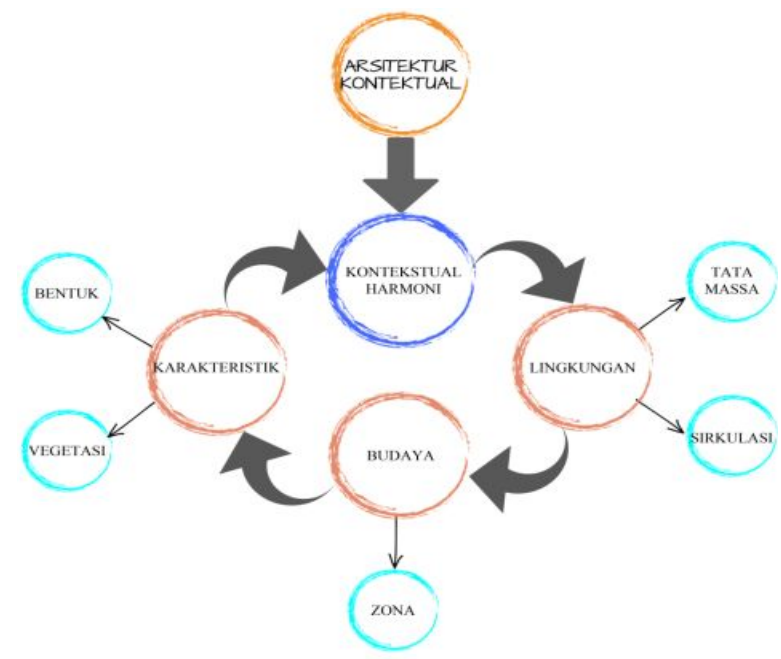

Gambar 65 Konsep Programatik

Kontekstual adalah konsep program yang digunakan pada kawasan Resort Pantai Kabupaten Kotabaru.

Menggunakan Kontekstual untuk konsep tersebut dikarenakan daerah tersebut memiliki potensi alam yang sangat baik untuk dikembangkan dan dijaga saat sebuah resort yang dirancang agar tetap menjaga keselarasan dan keindahan lingkungan dengan menjadikan 3 hal yang penting didalam Kontekstual Harmoni, yaitu Lingkungan, Budaya, dan Karakteristik.

\section{B. Konsep Lingkungan Pada Kontekstual Harmoni}

\section{Konsep Kawasan}




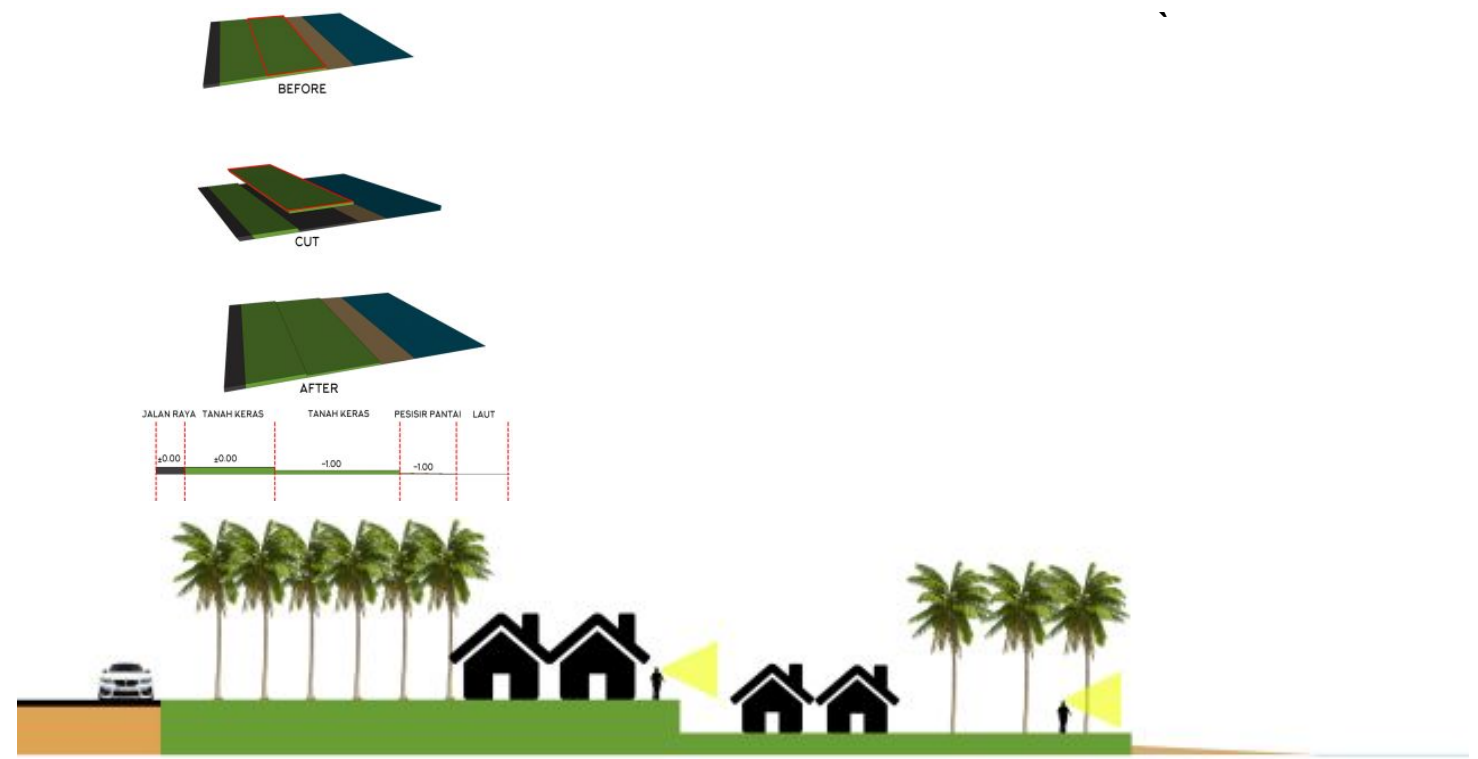

Gambar 66 Konsep Kawasan

Untuk kawasan yang dibangun menggunakan sistem "CUT" agar setiap bangunan yang berada di belakang tidak terlindungi oleh bangunan yang berada di depannya. sehingga, untuk view terhadap masing-masing bangunan tidak terganggu dan memaksimalkan pandangan dari bangunan ke objek yang terlihat.

\section{Konsep Zoning Kawasan}

Zona yang berada pada resort ini dibagi menjadi 3 zona yang akan di bangun, yaitu Zona Daratan, Zona Pesisir, Dan Zona Perairan.

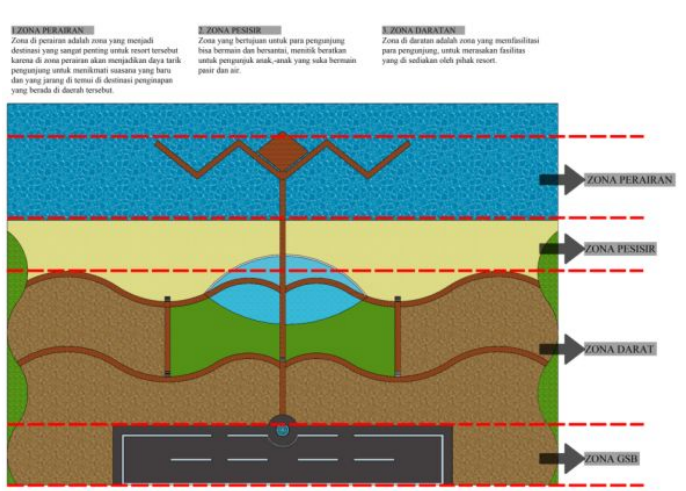

Gambar 67 Zona Tapak Pada Tata Kawasan

Tata kawasan pada Resort Pantai Gedambaan Kabupaten Kotabaru akan terbagi menjadi 4 zona yaitu, Zona Privat, Zona Publik, Zona Service, dan Zona Barrier.

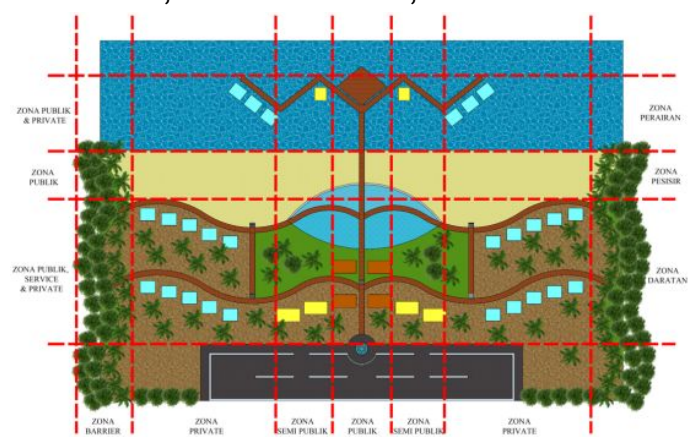

Gambar 68 Pembagian Zona Kawasan

\section{Fungsi-fungsi Bangunan Pada Kawasan}

Bangunan pada kawasan Resort Pantai Kabupaten Kotabaru memiliki 17 fungsi yang akan dirancang, terlihat oleh gambar berikut : 


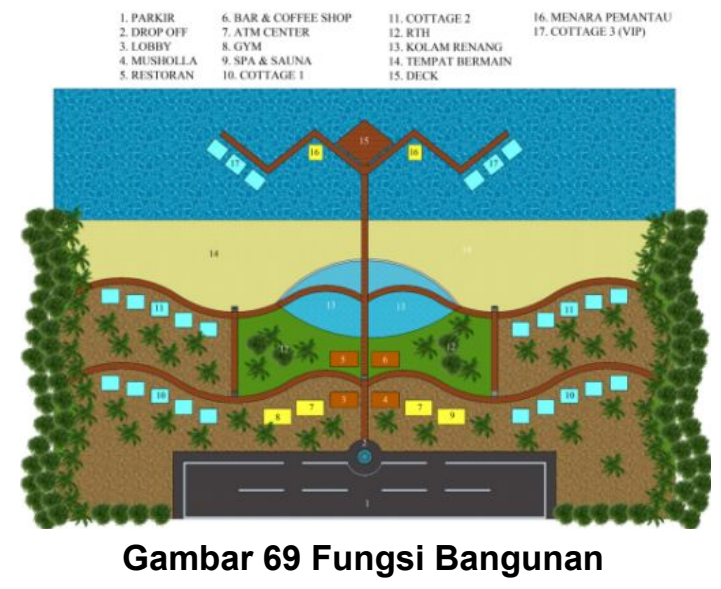

C. Konsep Budaya Kontekstual Harmoni

1. Interior Berdasarkan Budaya

Untuk Konsep kebudayaan yang diterapkan pada Kawasan Resort Pantai Gedambaan Kotabaru terletak pada interior setiap Cottage yang akan di bangun. Seperti : a. Jawa

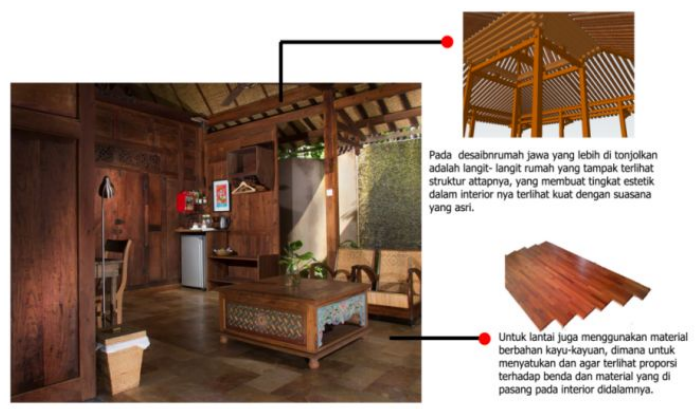

Gambar 70 Interior Jawa

Untuk interior kebudayaan jawa akan dominan menggunakan kayu jati yang pada dasarnya kayu jati adalah material utama pada cottage jawa dikarenakan keindahan dari tekstur kayu itu sendiri bisa memperlihatkan suasana yang lebih elegan dan terlihat tampak nyaman.

b. Dayak

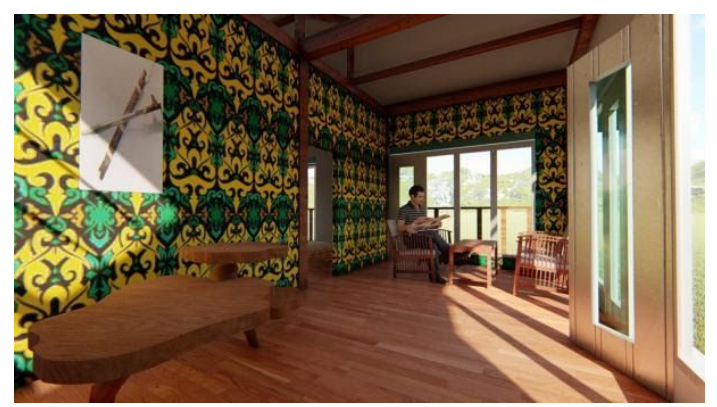

Gambar 71 Interior Dayak

Penerapan motif-motif pada interior cottage adalah untuk memperlihatkan sebuah ciri dari kebudayaan dayak yang dimana akan memperkuat estetik di dalam ruangan tersebut, dan pengunjung yang memasuki cottage tersebut akan terasa seperti berada di dalam rumah budaya dayak, karena motif-motif tersebut adalah ciri khas yang sangat kental bagi suku dayak.

c. Bugis

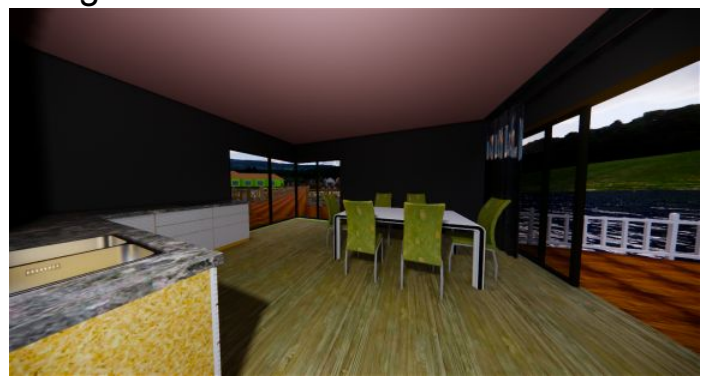

Gambar 72 Interior Bugis

Dikarenakan letak cottage bugis yang berada tepat di atas laut maka interior yang ditampilkan semaksimal mungkin memberikan bukaan yang besar agar pengunjung melihat keindahan pantai yang yang terpampang luas dari dalam cottage.

\section{Konsep Karakteristik Kontekstual Harmoni}

\section{Konsep Bentuk Bangunan}

a. Lobby

Lobby adalah salah satu tempat yang berada di sebuah bangunan digunakan untuk tempat menunggu para tamu yang akan check in maupun check out dan tempat pertemuan para tamu. 

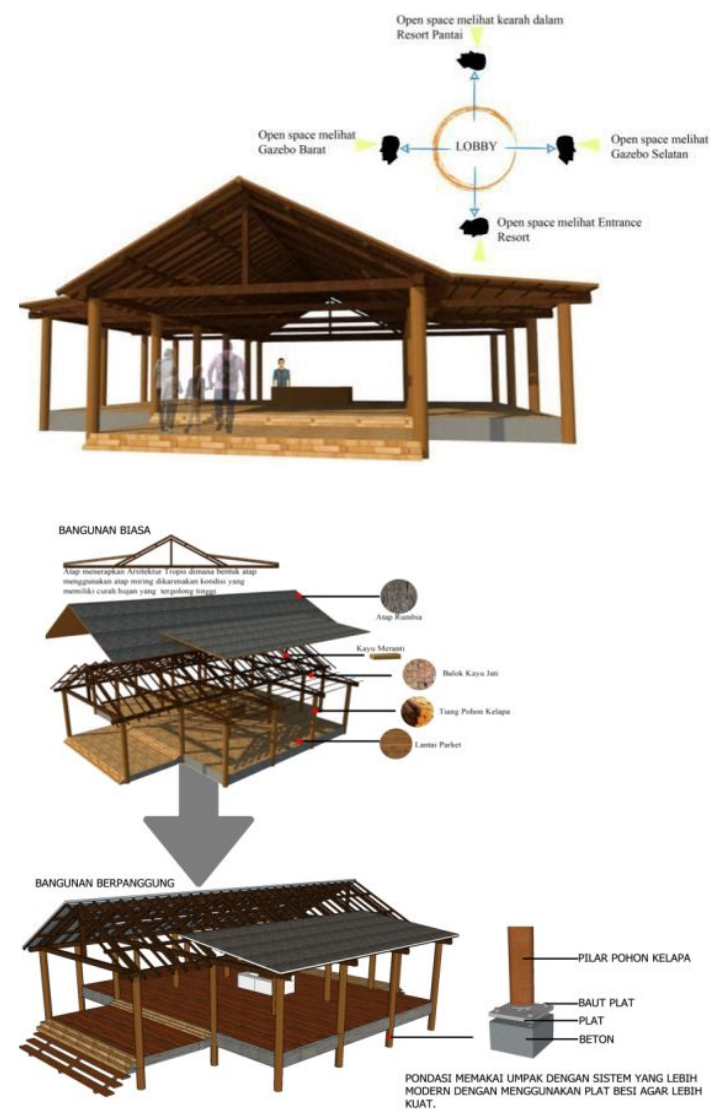

Lobby pada Resort Pantai di Kabupaten Kotabaru menggunakan prinsip Open Space pada view nya dari dalam hingga keluar dan untuk konsep material dan teksturnya menggunakan Konsep Kontekstual Harmoni dimana sebuah tekstur dan material yang bisa menyatu dengan alam sekitar dengan bahan-bahan yang mudah didapat di area sekitar kawasan, untuk harmoni sendiri material yang diberikan akan membuat rangsangan terhadap jiwa pengunjung itu untuk merasakan bagaimana suasana yang nyaman dan indah pada ruangan tersebut.

b. Restoran

Restoran terletak pada Zona Fasilitas dimana zona tersebut adalah zona inti dari kawasan tersebut restoran yang mempunyai High Angle View pada bangunan nya tersebut mempunyai 2 pembagian tempat yaitu pembagian pada area luar restoran dan area dalam restoran.

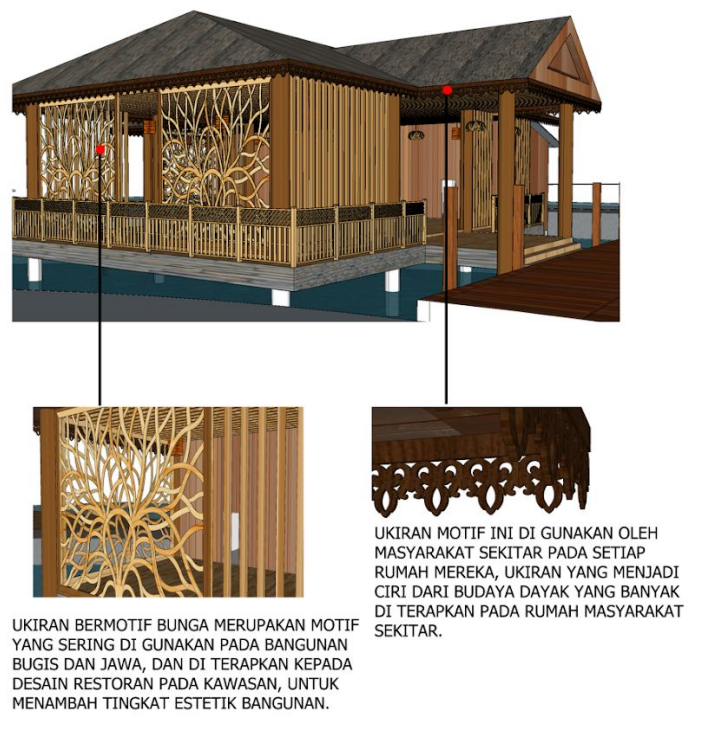

\section{c. Cottage}

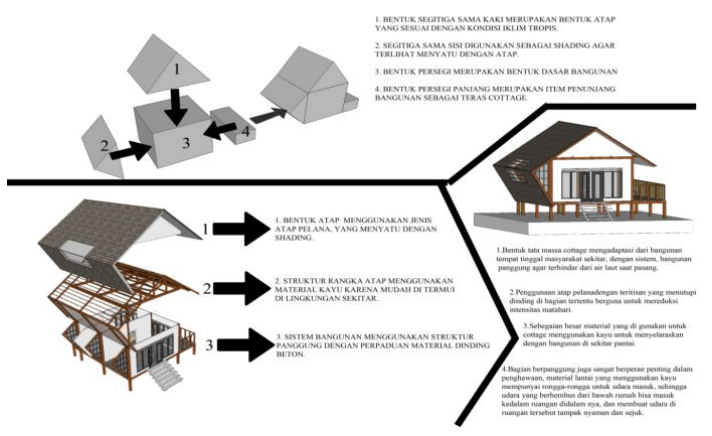

Untuk cottage menggunakan konsep yang mengikuti karakter rumah yang berada di sekitar kawasan yaitu :

- Penggunaan atap pelana yang kebanyakan di lingkungan tersebut rumah-rumah menggunakan atap jenis pelana

- Berpanggung

- Menggunakan struktur kayu yang dikombinasikan dengan dinding bata.

- Penggunaan pondasi batu kali yang menjadi mayoritas pada bangunan di sana.

\section{Konsep Massa Bangunan}

Bangunan yang dirancang pada kawasan Resort Pantai Gedambaan Kabupaten Kotabaru menerapkan konsep bangunan yang mengaplikasikan dan mengadopsi dari bangunan yang berada di sekitar lingkungan tersebut entah itu dari tata 
ruang ataupun dari bentuk bangunan. Hal itu untuk menguatkan karakter lingkungan yang berada di sekitarnya.

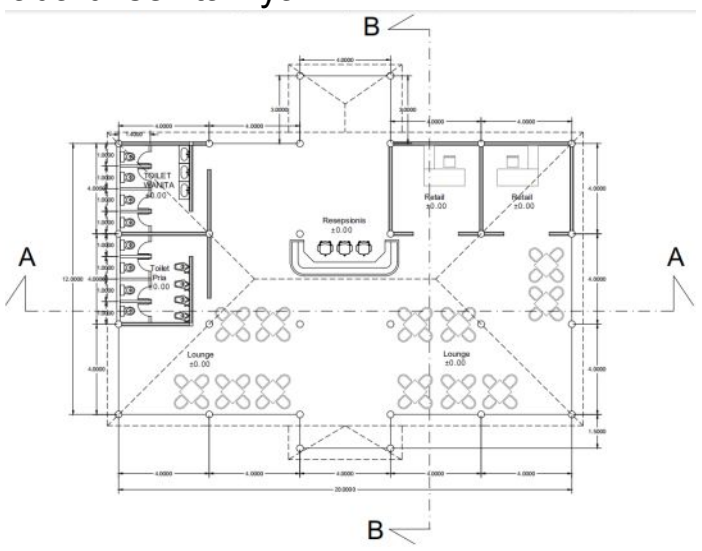

Gambar 73 Denah Lobby Entrance

Lobby Entrance menerapkan konsep terbuka agar pengunjung yang berada di sana bisa melihat apa saja yang ada di kawasan tersebut dan langsung bisa melihat kondisi resort yang mereka kunjungi.

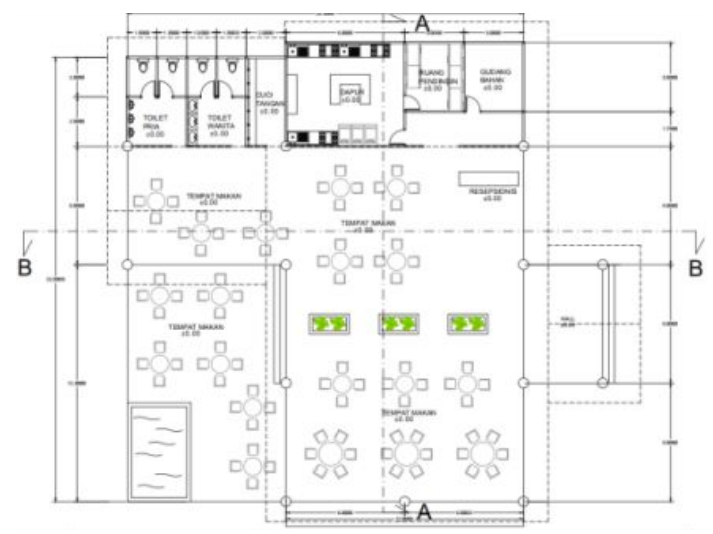

Gambar 74 Denah Restoran

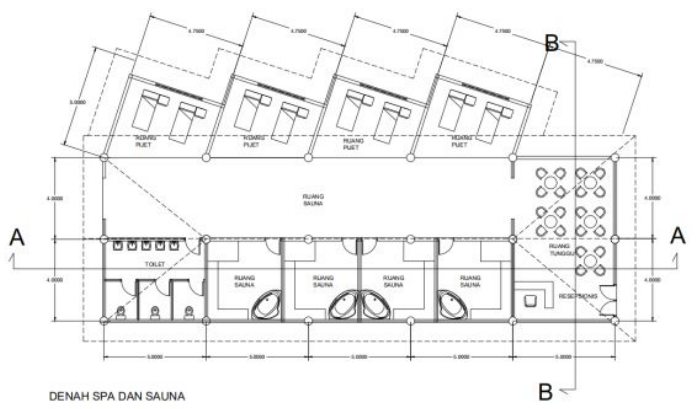

Gambar 75 Denah Spa \& Sauna

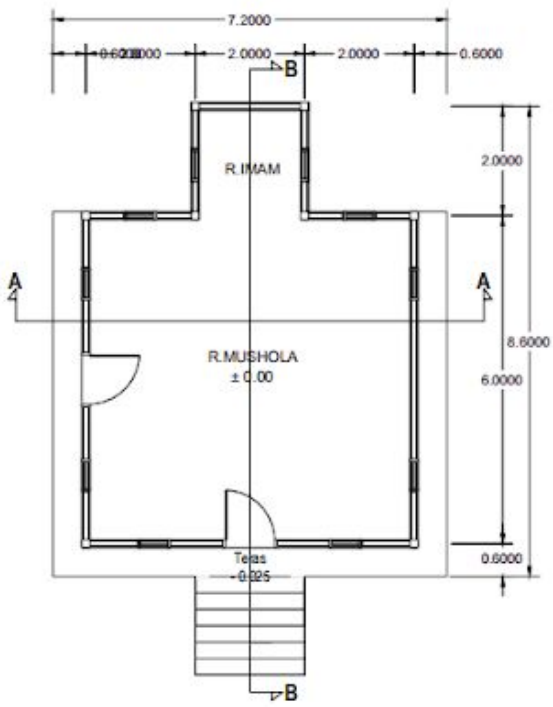

Gambar 76 Denah Mushola
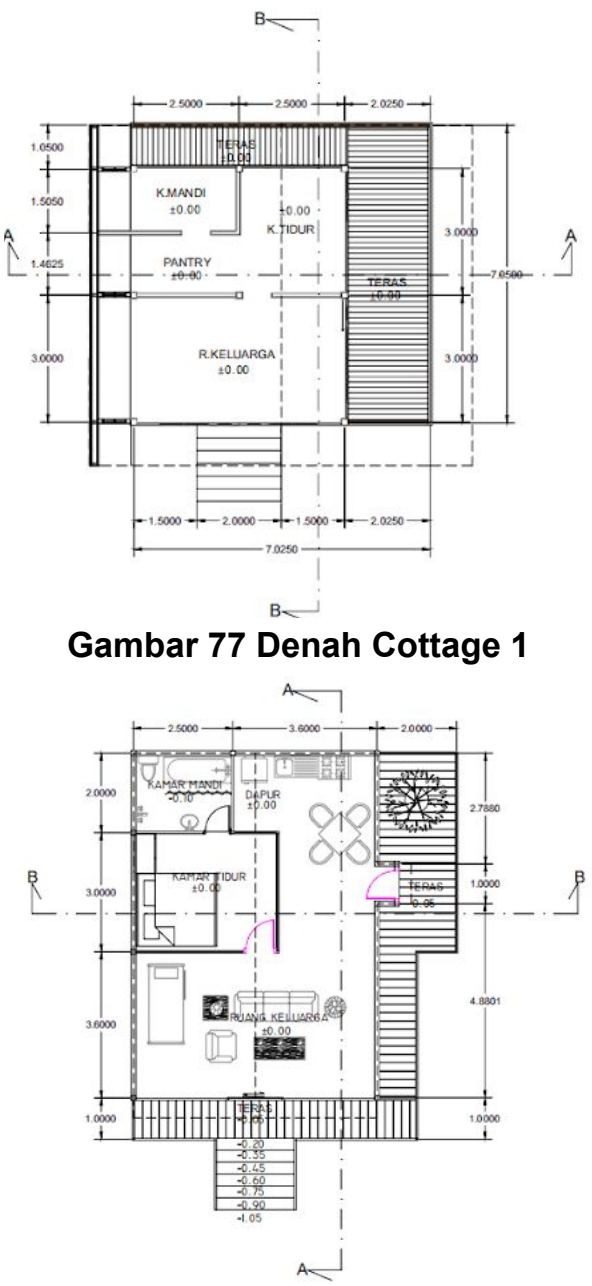

Gambar 78 Denah Cottage 2 


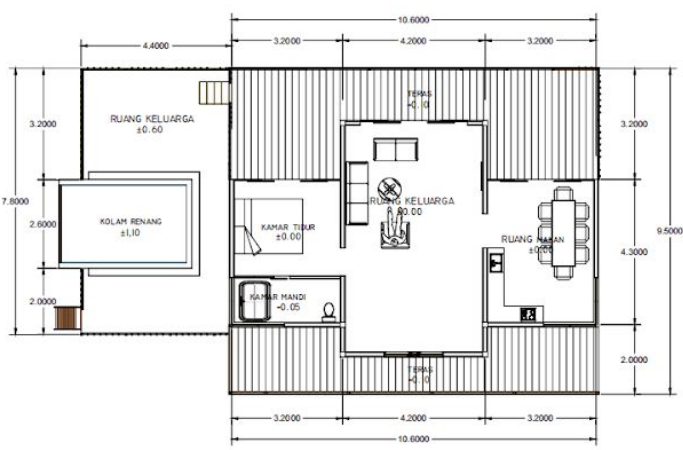

Gambar 79 Denah Cottage 3

3. Konsep Ruang Luar

Untuk ruang luar diterapkan konsep lingkungan dan karakteristik yang terdapat pada Kontekstual Harmoni, untuk mendapatkan kesan keselarasan dan penataan massa yang baik dan menjaga lingkungan agar tetap nyaman.

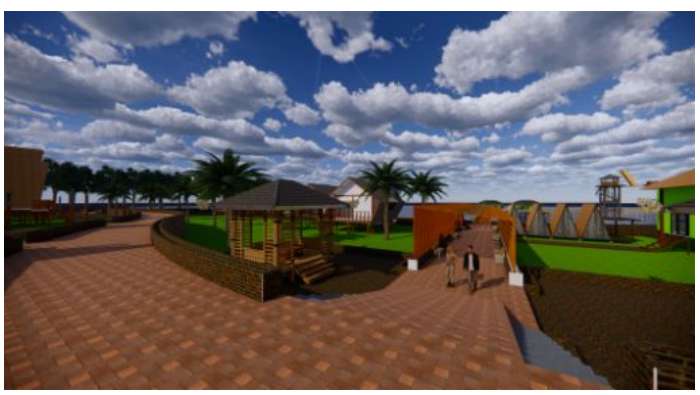

Gambar 80 Eksterior 1

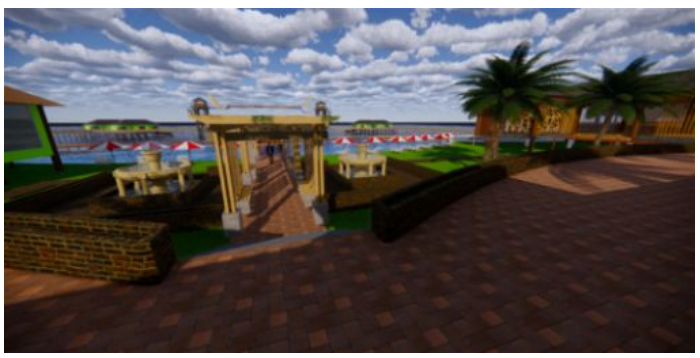

Gambar 81 Eksterior 2

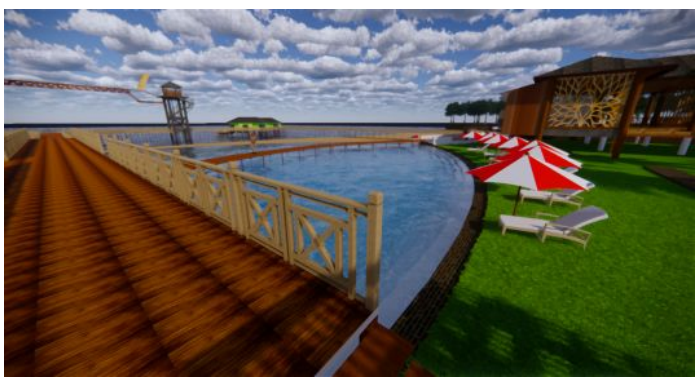

Gambar 82 Eksterior 3

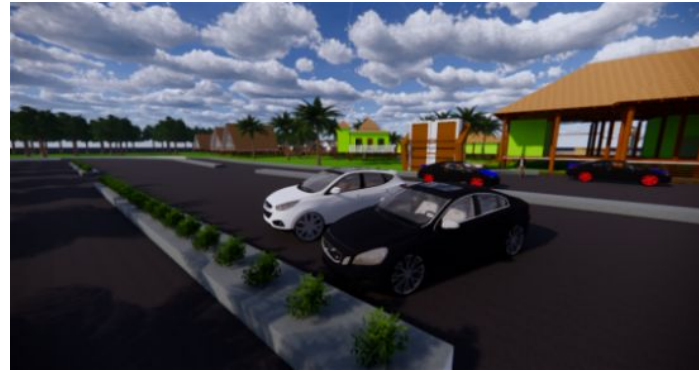

Gambar 83 Eksterior 4

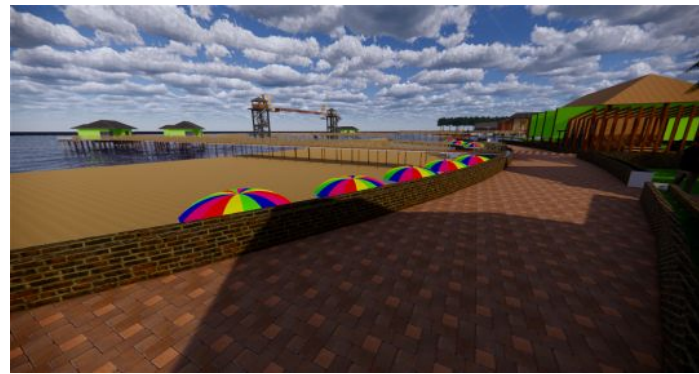

Gambar 84 Eksterior 5

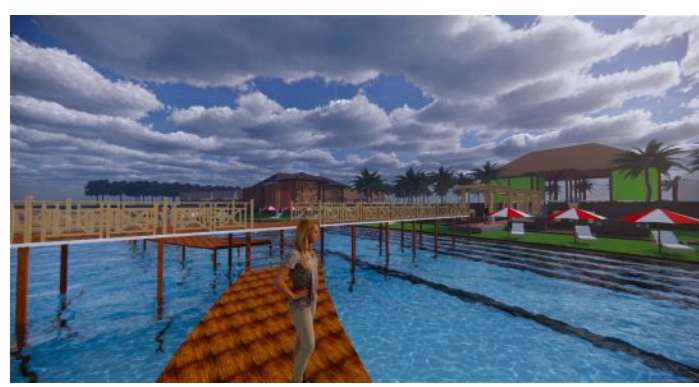

Gambar 85 Eksterior 6

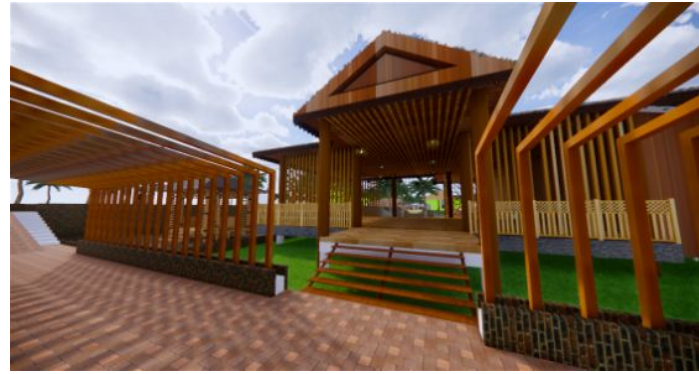

Gambar 86 Eksterior 7 


\section{E. Hasil Desain}

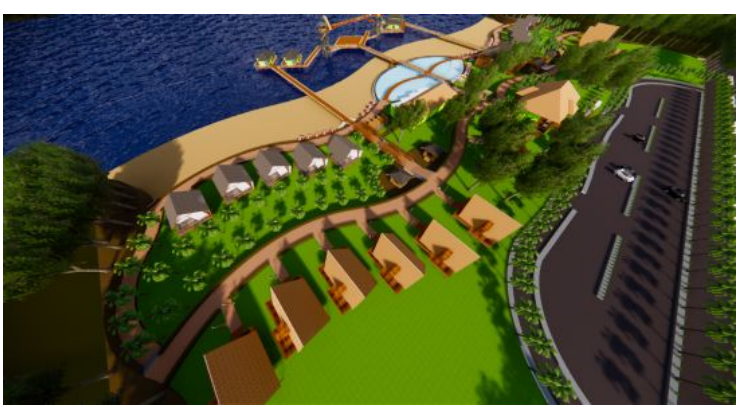

Gambar 87 Kawasan

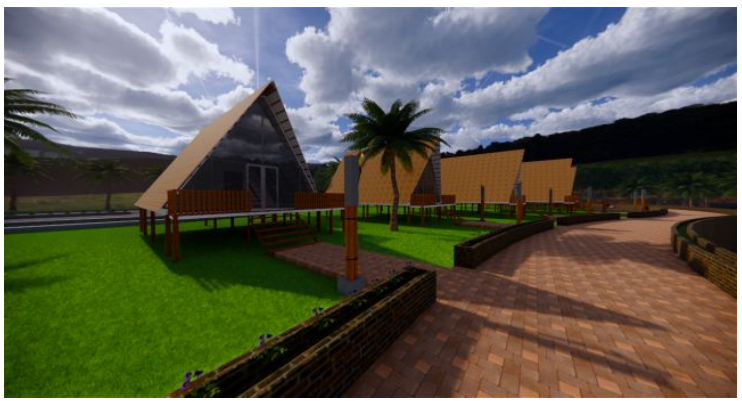

Gambar 88 Cottage 1

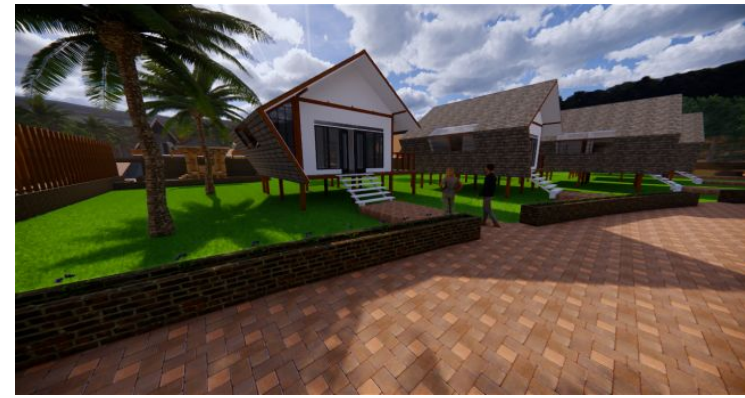

Gambar 89 Cottage 2

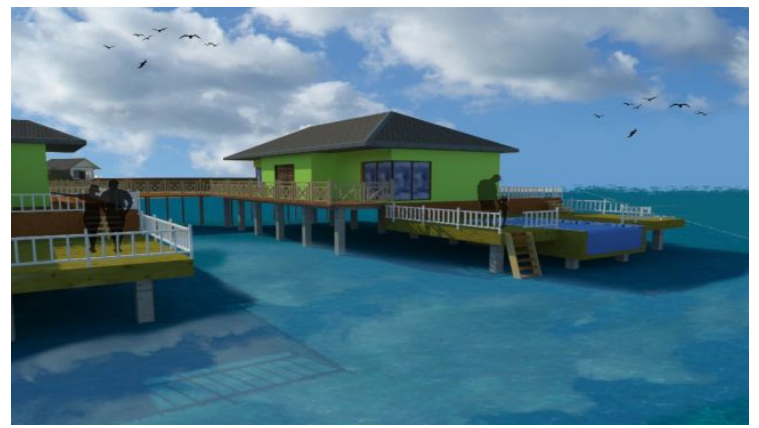

Gambar 90 Cottage 3

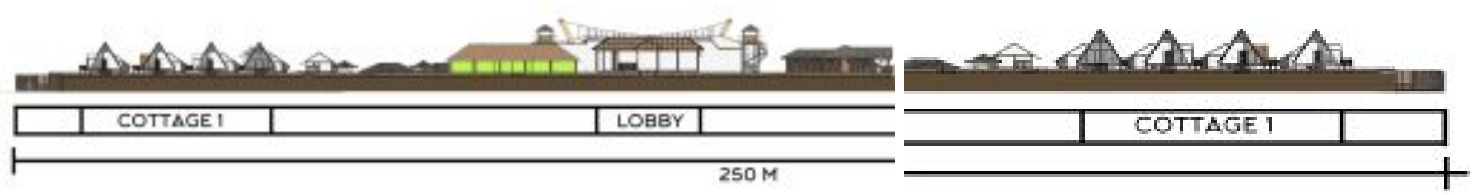

Gambar 91 Potongan Kawasan

\section{KESIMPULAN}

Permasalahan Arsitektural pada sebuah Resort Pantai Kotabaru adalah Bagaimana merancang sebuah resort yang mengembangkan potensi kawasan dengan membentuk suatu karakter berdasarkan Konsep Kontekstual pada kawasan Resort Pantai ?. Untuk mencapai sebuah hasil yang diinginkan maka memecahkan masalah menggunakan metode Kontekstual Harmoni menekankan pada (Menjaga jiwa dan karakter tempat), (Mengaitkan bangunan baru pada lingkungan sekitar), dan (Memperhatikan karakteristik objek-objek yang berada di sana).

Kontekstual harmoni dibagi lagi menjadi 3 unsur yaitu Lingkungan, Budaya, dan Karakteristik, dimana lingkungan yang dirancang menjadi suatu tata masa yang terlihat harmoni dan asri bagi pengunjung, untuk budaya sendiri menerapkan sebuah penzonaan pada cottage yang memperlihatkan kebudayaan yang menjadi mayoritas pada lingkungan tersebut, dan untuk karakteristik sendiri menggunakan bentukan yang dapat menyatukan sebuah objek-objek pada lingkungan sekitar seperti, bangunan yang kebanyakan merupakan bentuk panggung dan vegetasi yang menjadi ciri khas di pesisir pantai seperti pohon kelapa.Dengan dilakukannya perancangan pada Kawasan Resort Pantai Gedambaan di Kabupaten Kotabaru, maka diharapkan dapat menjadi tujuan wisata yang memberikan kenyamanan bagi pengunjungnya.

\section{DAFTAR PUSTKA}

Amboro, Mawardi Martina. (2015). Jung Para Resort Hotel Ekowisata Mangrove Di Pantai Semat Jepara. Semarang: Fakultas Teknik Universitas Negeri Semarang 
Brolin, B.C. (1980). Architecture in Context. New York: Van Nostrand Reinhold Company.

Dirjen Pariwisata,(1988:13) Definisi Hotel Resort Indonesia, Direktorat Jendral Pariwisata, Indonesia.

Nyoman, S. P. (1981). Ilmu Pariwisata. Jakarta: Pradya Paramita.

Statistik Pariwisata Kabupaten Kotabaru tahun 2017 (2017). Pantai Gedambaan : Dinas Kebudayaan Dan Pariwisata Kabupaten Kotabaru.

Laporan Pembuatan DED Pantai Gedambaan Kotabaru tahun 2018 (2018). Pantai Gedambaan : Dinas Kebudayaan Dan Pariwisata Kabupaten Kotabaru.

Yoeti, Oka A. (1996). Pengantar IImu Pariwisata. Bandung: Angkasa.

(2019). Diambil kembali dari https://arsitekturbicara.wordpress.com/2 012/05/19/studi-literatur-mengenai-arsite ktur-kontekstual/

(2019). Diambil kembali dari https://elib.unikom.ac.id/files/disk1/434/jb ptunikompp-gdl-dinaaliyas-21654-4-bab 3el-a.pdf

(2019). Diambil kembali dari http://thebatabatastudiodesain. blogspot. com/2009/07/kontekstualisme-dalam-ars itektur.html

(2019). Diambil kembali dari https://pesona.travel/keajaiban/4469/ma kna-dari-uniknya-arsitektur-rumah-adat-s uku-bugis

(2019). Diambil kembali dari https://pesona.travel/keajaiban/1783/sen i-ukir-suku-dayak

(2019). Diambil kembali dari

https://batam.tribunnews.com/2018/07/1 0/mengenal-rumah-jawa-bentuk-bangun an-dan-simbol-status-sosial-di-baliknya 